\title{
PARA UMA FENOMENOLOGIA DAS IDADES DA VIDA
}

\author{
For a Phenomenology of the Ages of Life \\ Por una Fenomenologia de las Edades de la Vida
}

Rui DE SOUZA JOSGRILBERG

\begin{abstract}
Resumo: Trata-se de um estudo da fenomenologia generativa do último Husserl que abriu a possibilidade de estudos de fenomenologia das idades da vida. As idades da vida são compreendidas como sínteses integradoras sucessivas do corpo motrício em sua relação de sentido com o mundo. A materialidade vivida do sentido no corpo é tomada como primeiro modo de intencionalidade. A relação de sentido se constitui em relação com os outros e de modo intersubjetivo. As idades da vida, nas três primeiras sínteses, são categorizadas segundo a apropriação do sentido em relação com a linguagem e conforme a tradição clássica latina: infans (não ou pré-falante), puer (a criança falante) e adulescens (síntese integradora de uma nova narrativa de si em relação com o mundo). Palavras-chave: Idades da vida, Generatividade, Corpo motrício, Relação e apropriação de sentido, Infans, Puer, Adulescens.
\end{abstract}

Abstract: Our point of depart is the generative phenomenology of the last phase of Husserl that opened the possibility for phenomenological studies of the ages of life. The ages of life are understood as successive and integrative syntheses of the body motricity in its relation to the meaning of the world. The lived materiality of meaning in the body is taken as the first mode of intentionality. The relation of sense is constituted with others by intersubjectivity. The ages of life, in its first three syntheses, are categorized according to the appropriation of meaning in relation to language and following the classic Latin tradition: infans (not or pre-speaking), puer (the speaking child) and adulescens (the need new narrative of self in relation to the world).

Keywords: Ages of life, Generativity, Body motility, Relation and appropriation of meaning, Infans, Puer, Adulescens.

Resumen: Trata-se de la propuesta de un estudio desde la fenomenología generativa del último Husserl que abrió la posibilidad para estudios de fenomenología de las edades de la vida. Las edades de la vida se entienden como la síntesis integradoras sucesivas del cuerpo motrício en su relación de sentido con el mundo. La materialidad vivida del sentido se toma en el cuerpo como el primer modo de intencionalidad. La relación de sentido se constituye en relación con el otro e de manera intersubjetiva. Las edades de la vida, en las tres primeras síntesis se clasifican de acuerdo a la apropiación de sentido en relación con el lenguaje y de acuerdo con la tradición clásica latina: infans (sin o pre-lingüístico), puer (el niño de falante) y adulescens (síntesis integradora en vista de una nueva narrativa de sí mismos en relación de sentido con el mundo).

Palavras-clave: Edades de la vida, La generatividad, Cuerpo motrício, La relación y la apropiación de sentido, Infans, Puer, Adulescens.

\section{Introdução}

O ser humano cumpre ciclos temporais com seu corpo existindo entre disposições da natureza e da cultura. São fases humanas que se desdobram no tempo e podem ser compreendidas em relação a elas mesmas como ciclo e em relação ao todo das fases. São sínteses integradoras que se desenvolvem uma sobre a outra. Essas fases acontecem como um processo de interação entre pessoas e como um processo generacional de pessoas na natureza, essa já modificada pela cultura. O ser humano em cada idade apresenta um conjunto de necessidades e de possibilidades a serem desdobradas e apropriadas ${ }^{1}$. Podemos questionar se é possível fazer uma fenomenologia desse modo de ser que vive o entrelaço do que a natureza faz

\footnotetext{
A ideia de apropriação, que aparece muitas vezes no texto, não significa tomar posse instrumentalmente. A encarnação é um modo de apropriação. O termo será usado para significar apropriação de sentido, isto é para mostrar a inclusão de sentido no movimento do corpo próprio, no movimento de si próprio, no movimento intencional de si mesmo.
}

conosco e do que fazemos com a natureza em seus primórdios humanos². Isto é, trata-se de ver não só o que nossa subjetividade faz com as coisas, mas também o que a bios faz conosco mesmo interagindo com a cultura. Essa questão implica o modo de constituição que acontece através do outro nas várias etapas da vida humana, do embrião ao sujeito responsável no mundo. Para Husserl (2013) trata-se de "fenômenos de fronteira", título do volume XLII da Husserliana ${ }^{3}$. Como podemos pensar fenomenologicamente o corpo desde antes do nascimento, quando só temos uma pré-constituição sem subjetividade do embrião, mas nos primórdios da psique do feto, tudo antes da apropriação de si pela consciência intencional. Tudo parece confluir num "sistema de intencionalidades" que começa com o corpo e onde o compartilhamento intencional do outro parece decisivo. Como veremos implica em um modo especial de fenomenologia e um diálogo respeitoso entre fenomenologia e ciência.

\footnotetext{
Segundo a conhecida expressão de Kant, no seu curso de Pedagogia. 3 Cf. Husserliana (daqui em diante, Hua).
} 
Os estudos sobre a criança, nas últimas décadas, mudaram a visão que tínhamos dela, mesmo para o não especialista. Referência a estudos das idades da vida são encontradas em origens remotas, desde a antiguidade clássica. Os antigos romanos, tais como Cícero (De officciis) ou o último acadêmico hispano-latino, Isidoro de Sevilla (Etymologiae), já falavam do infans, do puer, do adulescens, do adultus, do senior, do senectus, como o curso da vida humana (Séville, sem data). Mas é no século XX que esses estudos adquirem o caráter científico. No século passado publicou-se bastante, por exemplo, na Psicologia, na Pedagogia, na Antropologia, na Psicanálise, na Medicina, na Biologia, na Sociologia, Neurociência, entre outras rubricas; avanços recentes e importantes aparecem nas pesquisas em Psicomotricidade. A Psicanálise já nasceu em meio a remissões às primeiras fases da vida em S. Freud, M. Klein, D. Winnicott, J. Lacan, entre outros. Na Psiquiatria e Psicologia os estudos se concentram na psicogênese e Psicologia do desenvolvimento e na Neuropsiquiatria matérias nas quais se sobressairam H. Wallon, J. Bowlby, R. Spitz, J. Piaget, D., J. de Ajuriguerra, L. Vygostsky, C. Bühler, C. Gesell, J. Bruner (Pedagogia), W. Stern, R. Guardini, R. Zazzo, etc. Na Antropologia e Sociologia são muitos os estudiosos que se dedicam a fases da vida, mas destacamos os trabalhos recentes de David Le Breton pelo seu enfoque fenomenológico, especialmente na adolescência. São alguns dos que legaram estudos importantes na área. A lista poderia ser muito ampliada.

Além da evidencia fenomenológica, hoje são os dados empíricos que comprovam que o desdobramento do ser humano no útero é continuamente uma interação entre a esfera cultural dos seres humanos e "natureza", natureza marcada pelo horizonte humano desde o princípio. O corpo humano que gera traz a natureza já modificada para o modo de ser humano, i.e., a natureza replica as disposições humanas já sedimentadas pela natureza. No processo geracional a natureza continua a receber novos aportes humanos que ligam a natureza ao mundo humano e ao modo ativo de ser humano, p. ex., no desdobramento fetal encontramos evidências de uma psique que reage a outra (a mãe) e aos estímulos que lhe chegam de fora ${ }^{4}$. O desenvolvimento do psiquismo no feto apresenta sinais de sedimentação e reações emocionais. O estágio pré-natal da vida humana não é apenas uma preparação sem psique para o nascimento, mas um elo geracional onde começa o desdobramento com as relações de sentido, ainda que passivamente ${ }^{5}$.

\footnotetext{
4 Evidências científicas mostram que o feto interage com fatores conscientes e inconscientes da mãe, com registros que o acompanharão em sua história.

5 Spitz (1954). Com os avanços da ciência sobre o ciclo fetal algumas das teses do Dr. René Spitz do feto sem psique não se sustentam mais. $\mathrm{O}$ estado indiferenciado inicial avança em síntese integradora da fase fetal final para os primeiros sinais de uma psique reativa que se sedimenta especialmente em interação com o comportamento materno.
}

O nexo geracional torna incontornável o diálogo com as ciências; os resultados científicos se sedimentam no mundo da vida se tornam parte dela, e a ciência que deságua no cotidiano se faz também solo fenomenológico do mundo da vida. É o caso, por exemplo, do conhecimento que temos hoje do contexto de procriação, dos cuidados cotidianos da gravidez, das condições gerais do feto, etc. e que se tornam dados conhecidos por todos e sobre os quais perguntamos pelo sentido. Mas, as fases da vida não são só constatação empírica; são caminhos onde acontece o diálogo da natureza e do que conhecemos dela com o que intuímos com o acesso transcendental aos sentidos e significações. Com os grandes avanços da ciência a respeito da criança, seus resultados são importantes para que os sentidos das fases sejam mais bem compreendidos.

Na fenomenologia o estudo das idades da vida revelou-se como uma tarefa complicada que Husserl teve que enfrentar a partir de suas preocupações genéticas nos anos vinte e se intensificando em sua última fase. Essa preocupação que aparece fortemente em Husserl repercute em Merleau-Ponty, e outros que, excepcionalmente, dedicaram trabalhos fenomenológicos aos ciclos do corpo natural e existencial. A perspectiva dos ciclos da vida em relação com o mundo, a comunidade, a história e a intersubjetividade transcendental é de suma importância para a compreensão e interpretação do ser humano. Repercute em todas as outras áreas do conhecimento. A diversidade humana das fases da vida com as quais o ser humano está continuamente remetido, o acompanha em toda parte e em todo tempo.

A importância da fenomenologia dos ciclos humanos que constituem sua vida foi plenamente reconhecida por Eugen Fink, o colaborador de Husserl. Na América Latina o tema foi retomado pelo Dr. Roberto Walton (2002), na Argentina, em algumas de suas publicações ${ }^{6}$. É esse fenomenólogo que nos chama a atenção para a tentativa de Fink em sistematizar os temas husserlianos: No "Plano para o sistema de uma filosofia fenomenológica de Edmund Husserl”, que Fink escreveu e apresentou a Husserl em 1930, eaparece numa seção com o título Fenomenologia do protointencionalidad (fenomenologia dos "instintos"), no qual ele inclui os seguintes tópicos:

a) a protointencionalidade ainda indiferenciada: a

\footnotetext{
6 Principalmente em "Instintos, generatividad y tensión en la fenomenología de Husserl” (na revista Natureza Humana, São Paulo, 4/2, jul.-dez. 2002, p. 253-292, tema que reaparece em muitos outros artigos e livros. Devemos muito, nesta introdução, aos estudos do Prof. Walton, embora não o sigamos fielmente, como se verá. Preocupação semelhante, tem seu conterrâneo Patrício Perkins, " El vínculo madre-hijo como suelo del destino" (em Contrastes. Revista Internacional de Filosofía, vol. XVI (2011), p. 313-329.). Foi-nos útil o texto de Andrés Felipe López López, da Colômbia, "Vida humana fenomenológica. Balance sobre la relación entre sujeto humano y el sujeto trascendental en la fenomenología de Edmund Husserl.” (em Ideas y Valores 65.161,2016, p. 157-184); por fim cabe mencionar o ensaio de Rosemary y Rizo-Patrón de Lerner sobre "Constitución teleológica de la identidad, del instinto a la razón”, disponível na web em https:// textos.pucp.edu.pe/textos/buscar2.
} 
constituição resultante desse modo de ser. Formação de espaços de jogo de cinestesias. A finalidade intencional do protoimpulso, o problema do "inconsciente".

b) A Fenomenologia da protoassociação: formas de unidade pre-ônticas dos campos hiléticos. Fenômenos de fusão e individualização na esfera protopassiva ${ }^{7}$.

Toda essa linguagem com a qual Fink traça o plano da filosofia de Husserl retrospectivamente a partir de sua última fase, demonstra o quanto Husserl estava envolvido, na última década de sua vida, com os estratos de constituição do ser humano como um todo desde o embrião, o feto e a fase de apropriação mais ativa, marcadamente a fase da aquisição da linguagem. Os termos que Fink usa são husserlianos e mostram como suas investigações buscavam o enraizamento da fenomenologia genética no corpo com suas passividades alcançando o corpo em suas fases primeiras de formação em consonância com os outros: protointencionalidade ainda indiferenciada, a gênese de cinestesias, os protoimpulsos, os instintos, a unidade hylética do pré-existente, a esfera protopassiva. No progressivo enraizamento da fenomenologia no corpo, Husserl leva a fenomenologia genética até às esferas proto- e pré- onde começam os desdobramentos do corpo sem ainda ter chegado à consciencia, isto é, o corpo dependente dos nexos generativos e intencionalidades surdas transmitidos na relação com outros. Um traço essencial da fenomenologia das idades da vida é esse: nenhuma fase acontece sem compartilhamento intencional ou transmissão de sentido entre gerações. Desde o feto que sente até à velhice próxima do fim, a vida é sempre vida compartilhada.

Os estudos que se seguem nesse dossiê traduzem a preocupação de se pensar "fases da vida" como centro de uma preocupação antropo-ontológica fundamental e numa perspectiva fenomenológico-hermenêutica. Os trabalhos traduzem um leque complexo de preocupações metodológicas, que fazem referências a E. Husserl, M. Merleau-Ponty, P. Ricoeur, e Manuel Sérgio, português que partindo de Merleau-Ponty desenvolveu uma nova visão da prática da motricidade humana. O eixo que une os estudos que se seguem sobre as idades da vida é a relação de cada fase mantém entre o corpo motriz, o sentido e a linguagem.

\section{A fenomenologia das idades da vida: generatividade}

A fenomenologia traz com ela uma um modo de visar o ser humano e de concebê-lo em sua constituição subjetiva e intersubjetiva, suas relações com o mundo e a constituição de distintos mundos, sua condição social e histórica. Seu modo de ver e ler o mundo passa pela maneira de ver e ler a si mesmo. O ser humano é correlato de um

\footnotetext{
Walton. (2002, p. 258). A citação de Fink em Walton é da Hua XV, xxxix.
}

modo de co-estruturar o mundo com os outros como um horizonte de horizontes ${ }^{8}$.

O volume XV da Husserliana, que contem os textos de Husserl (1973) sobre a intersubjetividade e escritos entre os anos de 1929 a 1935, será uma fonte para começarmos a pensar numa fenomenologia das idades da vida. Nesse volume vemos projeto de Husserl de retomar geneticamente a questão da subjetividade, a subjetividade que se move intencionalmente para fora e para dentro, e reflete a vida psíquica em sua formação desde os estratos humanos mais recuados e profundos (como os instintos) em correlação com a vida das pessoas que participam desse processo genético. Husserl remonta ao estágio fetal do ser humano (e mesmo ao estágio embrionário), do ainda não nascido chamado de Urkind, ou a criança primal ou o proto-infante (Hua, 595), o feto que já sedimenta sensações que orientam o corpo (Hua, 604 ss) e habilitam os instintos para vida. Nesse nível de intencionalidade pré-reflexiva a subjetividade é pré-constituída como um movimento do ser humano em direção à consciência reflexiva. Nela se constituem as predisposições para a constituição de um pré-mundo onde os sentimentos, a percepção, a ação e a linguagem serão inscritas. Husserl pressupõe um nexo geracional que vincula o feto em geração aos pais e à série de seres humanos que formam uma sequência genealógica dele com a natureza: "Todo ser humano se encontra, portanto, em 'nexo generativo' infinitamente aberto, no encadeamento e ramificação das gerações” (Husserl, 1073, p 178). Ou como diz Husserl (1973, p. 604); mais adiante e quase como uma máxima, escreve: "Os vivos despertam os não vivos" (Die Lebendigen wecken den Unlebendigen).

A antropologia fenomenológica é solidária da constituição de um mundo horizonte onde muitos mundos sub-horizontes são possíveis. Desde a Renascença tem-se a ideia de que o ser humano é vida em formação (p. ex., Pico de la Mirandola ou Erasmo ${ }^{9}$ ) e que se desdobra em diferentes etapas cada uma com seus mundos. Ver o ser humano no seu desdobramento é diferente de ver o ser humano só a partir do adulto. A mudança de sentido por fases implica em ver o indivíduo que se forma num meio ambiente sócio-cultural. Propomos ver esse desdobramento em fases pela fenomenologia. ${ }^{10}$ Não seguiremos, portanto, nenhum dos modelos consagrados da psicolo-

\footnotetext{
8 "Mundo" significa etimologicamente um horizonte organizado de coisas. "Mundus" em sua origem latina opõe-se a "i-mundus" como no grego "kosmos" se opõe a "chaos".

9 Cf. Erasmo, De Pueris, São Paulo, Ed. Escala, s/d. Erasmo defende a tese "o homem não nasce homem, mas torna-se homem", segundo apresentação de L. Ferracine (análogo ao “o animal é” e "o ser humano está sendo"); Cf. tb. Pico della Mirandola, De hominis dignitate oratio.

${ }^{10}$ Usamos o termo "desdobramento" com a significação que o aproxima da ideia husserliana de constituição. A ideia de constituição em Husserl não é isenta de ambiguidades. Mas, seguimos uma indicação de Paul Ricoeur que explicita o significado da constituição em Husserl (particularmente nas Ideen II: "Ai se percebe claramente que 'constituir' não é de modo algum construir, menos ainda criar, mas desdobrar as visadas da consciência confundidas na apreensão natural, irrefletida, ingênua, de uma coisa.” Ricoeur. (2009).
} 
gia genética ou da psicologia do desenvolvimento. Não podemos pressupor uma "natureza infantil" ou uma "natureza adolescente". O ser humano é visto em diferentes constâncias que sustentam seus desdobramentos mantendo a unidade. Vamos nos ater principalmente a três modos de ser abertos pela relação corpo-linguagem que pode ser dividia em três grandes fases: o modo infans (o não falante e pré-falante fetal e pós-parto), o modo puer (linguagem como etapa de apropriação ou formação do próprio), o modo adulescens (refiguração do corpo e da linguagem em novos modos de relação com o mundo e com os outros). Todo modo de ser dessas fases dependem de um elo inter-humano (A. Hesnard, 1957), relações com as pessoas que vivem fases distintas e as relações que ocorrem no mundo cotidiano onde as formações culturais são importantes (o ser humano não é só natureza, mas o entrelaço natureza-cultura).

Husserl mantém a ideia de um devir humano por etapas, desdobramentos de elos entrelaçados, que vai dos primeiros movimentos e habitualidades do ser vivo até às sínteses da razão: "Razão é uma specifcidade do homem, tanto em atividades pessoais como habitualidades dele como ser vivo. Sua vida é um permanenente devir pessoal resultado de uma permanente intencionalidade de desenvolvimento. E nesta vida em devir o devir é a própria pessoa. O seu ser é um constante tornar-se, e isso vale tanto para a interação entre a pessoa individual e a pessoa-comunidade (Gemeinschafspersonalem) tanto para os seres humanos como um todo formando uma humanidade una. A vida humana é um curso pessoal com etapas de auto-reflexão e de auto-responsabilidade, desde o ser reflexivo de particularidades (e atos ocasionais) até o nível de auto-reflexão e auto-responsabilidade universal pela aquisição da consciência de autonomia, da idéia de uma vontade livre e bem determinada, formando com sua vida pessoal uma unidade sintética de uma vida universalmente responsável... (Husserl, 1952, p. 272).

O ser humano se constitui como o lugar originário de manifestação do mundo. O modo de ser no mundo é axialmente constituído por uma variedade enorme de intencionalidades (corpóreas, pessoais consciente ou parcialmente conscientes, coletivas) que permeiam a materialidade do corpo vivido e o fluir da consciência. A intencionalidade humana mantém uma relação com o mundo em termos de sentido com possibilidades de apropriação que são essenciais ao modo de ser humano, não exclusivamente, mas especialmente através da linguagem.

A fenomenologia nasceu da consciência intencional, logo entendida como consciência transcendental. Por sua constituição intencional o ser humano se forma nessa disposição axial como leitor do mundo e capaz de refletir sobre o mundo e agir nele. O mundo é seu horizonte. Em sua disposição originária para intencionar o mundo o ser humano é natureza modificada pela cultura desde seus modos primeiros de concepção (intrauterina) até o final do curso de sua vida. O ser humano vive nessa disposição que o faz intérprete transcendental do mundo. Transcendental é sua subjetividade intencionalmente formada na relação de sentido com as coisas. Entendemos, pois, como transcendental a vida subjetiva e intersubjetiva como uma relação, relação de sentido e relação de apropriação do sentido das coisas. A "consciência encarnada" é um modo transcendental do corpo em relação com o sentido. A consciência encarnada não é um subproduto de uma consciência transcendental absoluta. A subjetividade transcendental é um modo especial de relação vivida com o sentido das coisas e do mundo. Com isso deslocamos o transcendental husserliano, mesmo que provisoriamente e metodologicamente, de seu suporte na metafísica da consciência.

A subjetividade capaz de leitura do ponto de vista transcendental é uma subjetividade encarnada. E como relação o transcendental não é uma característica exclusiva da consciência (e sua tendência de super-abrangência), mas uma característica da vida humana como um todo, pois a vida humana como um todo é uma relação com o sentido das coisas (Lopez Lopez, 2016). Essa relação umbilical com o mundo transcendente (sua externalidade) e sua apropriação intencional pelo sentido, este significado na língua, será fundamental para a compreensão da relação corpo-linguagem e para a consciência de mundo. Uma língua particular (a língua portuguesa, por exemplo) se torna uma mediação, mas uma mediação essencial na apropriação do sentido em seu modo específico de significar.

Husserl (1973), com a expressão de "um começo transcendental da vida humana" estende a relação com o sentido às fases pré-falantes do corpo e seus desdobramentos em ciclos: “O 'começo transcendental' está dado inclusive desde o corpo ainda não nascido [intrauterino], pré- ou proto- infante (vorkindliche Monade ou Urkind ${ }^{11}$ ) porque já no recém-nascido existe o 'instinto orientado', experiências que se sedimentaram desde o seio materno que correspondem a horizontes perceptivos, dados, e campos sensoriais (Husserl, 1973, p. 605). Em ambos os níveis, isto é, da gestação e do nascimento, o ser humano é um pré-ego, uma unidade de afecções, de associações primárias e de instintos inatos corporais e biofísicos" (Lopez Lopez, 2016, p. 165).

O corpo é visto numa dimensão em que o nexo geracional oferece duas visões paralelas, uma da natureza que trabalha como natureza, e outra das apropriações intencionais, o que a natureza faz e o que o ser humano faz (sendo ele mesmo parte da natureza); essas visões paralelas da ciência e da fenomenologia são essenciais uma à outra, uma visão da natureza pela ciência empírica e outra a visão da fenomenologia que explora a relação especial com o sentido das coisas no mundo horizonte. As duas criam sedimentações no mundo da vida, nosso solo humano. Numa, fala a visão da natureza investigada pe-

\footnotetext{
${ }^{11}$ Ниа XV, 595
} 
la ciência, na outra fala a relação transcendental da vida com o sentido e a eterna busca humana pelo sentido das coisas, de si mesmo, do mundo.

O movimento da fenomenologia genética de Husserl vai em direção ao mais fundo da corporeidade, às formações de sínteses passivas, pré-reflexivas, ante-predicativas (como os instintos, p. ex,). Mas o ser humano é dado num percurso de vida onde o corpo antecede a consciência intencional. A consciência é consciência encarnada a partir de uma fase do corpo que se desdobra em fases temporais, o que indica diferentes modos de encarnação fazendo ciclos cujos sentidos precisam esclarecimento fenomenológico. A consciência encarnada não é algo que pode ser tratada uniformemente no percurso humano, do feto até os outros ciclos. A subjetividade constituinte é ela mesma geneticamente constituída. O ponto de vista transcendental revelado na consciência em sua atividade de constituição necessita complementos e extensão até às formações pré-reflexivas. A constituição transcendental da subjetividade não fica restrita à consciência encarnada. Somos obrigados a repensar o transcendental não restrito à consciência encarnada e seguir os passos de uma constituição passiva proposta por Husserl, porém indo além, na direção de um transcendental não dependente da idealização constituinte na consciência pura absoluta, reafirmando o transcendental do corpo e de uma sensibilidade transcendental. A extensão do transcendental à matéria e ao corpo relativiza o idealismo transcendental da consciência. Mesmo que a tratemos como uma relativização metódica é essencial para suspender pressupostos metafísicos e tratar a consciência transcendental como parte de uma relação transcendental de sentido que não se limita à consciência. Essa relação transcendental com o sentido não pressupõe que haja uma superconsciência transcendental que seja o fundamento. Chegamos a um limite aporético e produtivo, mas que não se resolve em termos de uma consciência antropocêntrica. $\mathrm{O}$ transcendental como relação não confunde começo originário com fundamento.

O transcendental é originariamente um ponto de vista privilegiado de visar o sentido, relação das coisas com o sentido das coisas. Seguimos com o transcendental husserliano, mas por assim dizer, metodologicamente sem metafísica, e pensado apenas como uma relação com o sentido em vários níveis possíveis. O transcendental em relação com o vivo é o modo sob o qual o sentido é continuamente reelaborado em estruturas intencionais de apropriação que o sustentam como relação a priori do vivido com o sentido. Assim o corpo pré-falante do feto já se comporta como uma estrutura transcendental a priori que se apropria e sustenta o sentido (sensível) e mantém relações de sentido pré-reflexivas. Já o corpo falante alcança outra estrutura de sustentação do sentido e mantém relações de sentido apropriado ao seu modo. O transcendental opera a visão da vida como uma relação de experiência de sentido que depende de estruturas de apropriação do corpo em fases para se desdobrar, on- de as relações com o sentido das coisas no mundo vão se tornando próprias, isto é, são incluídas no movimento do corpo próprio e de si próprio. O corpo revela diferentes níveis de apropriação que antecede a apropriação pela consciência de si. Husserl reconhece que temos aí um processo que precisa ser abordado com os recursos de uma fenomenologia que, depois, será identificada como fenomenologia generativa de um processo que desdobra entre pessoas: "a relação de Intersubjetividade e mundo já é sabido, põe em questão, o fato que eu, sobre a estrutura necessária da primeira infância, faço surgir uma segunda reconstruida, o que permite expressar a priori, o que acontece com a constituição "esquecida" da primeira. E só a necessidade essencial desse esquecimento a torna compreensível. Por que não começar com esse fenômeno? A partir do nosso modo de existência no mundo como processo de experiência constatamos que em qualquer fase da vida tem-se uma fundada estruturação de consciência: a apropriação dos entes = proveniência da motivação cinestésica direcionada para sentir os dados, e na passagem da apropriação como fenômeno. $\mathrm{O}$ que se manifesta não é possível se manifestar sem antes ter a sensação e a cinestesia etc., a experiência pura e primeira só é pensável como resultado de um processo." (Husserl, 2008, p. 468). O ego tem um começo originário, o seu nascimento transcendental, já no instinto direcionado para ele ("Das Ego im Uranfang (der Urgeburt) ist schon Ich gerichteter Instinkte") ${ }^{12}$.

O ponto de vista transcendental pressupõe uma fonte não empírica de relação com o sentido onde essa relação acontece. Desde esse ponto de vista mantém-se a impossibilidade de uma explicação satisfatória do ser humano, mas abre a possibilidade de um diálogo com as ciências na medida que as estruturas materiais das coisas e de corpo se prestam à observação empírica e regulação científica. O corpo próprio é um corpo centrado em especiais estruturas a priori de apropriação que o tornam corpo próprio. Exemplo, a motricidade do corpo intencional que sente em relação à consciência de si; o ser motriz humano sintetiza as primeiras relações como intencionalidade dos instintos, depois acede a outros níveis de apropriação em estruturas teóricas, volitivas, de sentimentos reorganizados.

Uma intencionalidade pré-consciente e constitutiva em termos de corporeidade (pré-constitutiva em termos de consciência) e que poderá ser apropriada parcialmente e fundar o percurso do sentido em termos de antes e depois, sustentando a sua dimensão compreensiva. O sensível é o intencional originário da constituição e se dá na fronteira indeterminada do passivo e ativo do corpo. Assim vivemos o jogo de passividade e atividade que percorre nosso corpo, a passividade e atividade da memória, passividade e atividade da imaginação, tudo na dialética

${ }_{12}$ Ms. B III 3/ 35a . Apud. Taguchi, Shigeru, Das Problem des,Ur-Ich` bei Edmund Husserl, Springer-Verlag, 2006, p. 118. 
do que o corpo faz conosco e o que fazemos com o corpo. Nessa dialética nasce a possibilidade da Psicanálise. As pulsões são apropriações do corpo e mostram um aspecto do que o corpo faz com a gente. Já são, como os instintos, intencionalidades corpóreas que podem ser reapropriadas em outros níveis. A Psicanálise tende a voltar-se, por um lado para a Biologia, e por outro, para a fenomenologia hermenêutica.

O compartilhamento de sentido entre corpos humanos acontece em vários níveis. Desde o sensível, até às formas de significação sistêmicas encontramos muitos níveis entrelaçados. O percurso do sentido no corpo vai do nascimento transcendental do bebê pré-falante, passa pelas relações com o corpo da criança falante, e se reconfigura como adolescência, e assim por diante, passando a outras fases de vida. Por outro lado, não podemos reduzir uma fase à outra. Fenomenologicamente as perspectivas "pré-" e "proto-" significam ao mesmo tempo constituição independente num momento e constituição dependente em outro.

O corpo responde a direções que são pré-subjetivas, isto é, disposições que preparam as estruturas de apropriação de sentido por ciclos de vida.

O ser humano entra numa dinâmica formadora com momentos não-reflexivos, pré-reflexivos e reflexivos. Entre a pura sequência natural e a esfera própria do ser humano que se forma por apropriação de suas possibilidades temos o princípio formador do ser humano como processo - princípio generativo do gênero humano - que o torna um ser de formação contínua.

O princípio generativo - ser em formação com base assentada de generatividade entre pessoas, relaciona seres humanos em diferentes fases, e fazendo-as interagir de modo integrado (Ex.: a relação mãe-bebê). O mistério desse modo de ser em desdobramentos nos aproxima do sentido mesmo do ser humano não apenas como finitude, mas como apropriação muito parcial de si mesmo: não nos pertencemos inteiramente. O desdobramento é socialmente coordenado. A disposição corpórea promove desdobramentos contínuos e cria possibilidades para a sustentação e formação da espécie e condições de transição de geração em geração. O ser humano é transformador, transfigurador, transcriador, como parte de um processo que o supera. O ser humano é corpo que se transcende, sendo ele mesmo transcendido, corporeidade capaz de abrir possibilidades e se comportar como dinâmica criadora na apropriação parcial de si. O impulso humano primordial (Ur-streben) é o desdobramento corpóreo em um si mesmo, em possibilidades limitadas de apropriação, mas capacidade humana de rejogo, de reefetivação, de reinvenção.

Cada fase, por sua vez, mostra desdobramentos específicos. Os desdobramentos fásicos acontecem um pelo outro ("intentionales Ineinander", segundo Husserl; quiasma, segundo Merleau-Ponty). As fases revelam paradoxalmente autonomia e interdependência.
O estudo fenomenológico das fases da vida abrange as três grandes modalidades da fenomenologia husserliana sob o regime da epochér ${ }^{3}$. A fenomenologia eidética, destaca aspectos essenciais de cada fase; a fenomenologia genética procura aclarar a constituição temporal ou o desdobramento do sentido de cada fase; a fenomenologia generativa, (entendida como um desdobramento da fenomenologia genética) procura aclarar os desdobramentos marcados pelo nexo generativo que envolve a cultura e as relações entre gerações. A fenomenologia das idades da vida pode ser tratada nos três caminhos fenomenológicos, mas adquire sua expressão mais ampla na fenomenologia generacional ou generativa, assim vista pelo próprio Husserl em seus últimos escritos.

A fenomenologia generativa opera como uma fenomenologia reconstrutiva das fases pessoais e sociais passadas. A latência e a patência implica um movimento de ir e vir. Tal procedimento foi vivamente tratado por Eugen Fink. P. Perkins escreveu a respeito:

A Fenomenologia regressiva explicita a subjetividade transcendental como correlato da experiência do mundo, levando a cabo sua pesquisa das unidades vitais da experiência, dos atos, e indo para a camadas mais profundas da vida transcendental constituinte. A fenomenologia construtiva, ao contrário, lida com todas as formações motivadas das unidades dadas na vida transcendental. O tema das crianças faz parte desta última..." (Perkins, 2011, p. 317).

Com a compreensão da cinestesia e os comportamentos percebidos ou constatados do feto, a nossa relação psicomotriz com a vida nos permite operar intencionalmente o sentido que acompanha o modo ser das fases que nos antecedem. A vida é um processo contínuo de sínteses passivas e de apropriações (inclusão no próprio) parciais de aspectos dessas sínteses predecessoras. O corpo humano estabelece um jogo de apropriação entre o passivo e o ativo de nossa consciência, que se prolonga como jogos de memória e imaginação, essenciais para a constituição do si próprio. A fenomenologia das idades da vida nos permite um esforço de reapropriação do que já fomos e do que somos hoje. É uma tarefa fenomenológico-construtiva, compreensiva e hermenêutica. Walton comenta os passos indicados por Fink para a fenomenologia construtiva:

"O 'Plano para o sistema de filosofia fenomenológica' de Edmund Husserl' (de E. Fink) inclui uma fenomenolo-

\footnotetext{
13 "Epoché" entendida como suspensão de toda explicação transcendente (causalidade externa à consciência) que são dadas por teorias, autores, hipóteses, explicações metafísicas ou científicas, etc.. Isto não significa que estejamos isentos plenamente de pressuposições ou que haja um interdito em articular o fenomenológico com considerações relevantes da ciência, abrindo assim o espaço para o diálogo entre o empírico da ciência e o fenomenológico de nossa investigação. De certo modo, a fenomenologia é ela própria a radicalização do empírico (empirismo transcendental, diz N. Depraz, (2007), cf. inter alia, Compreender Husserl, Petrópolis, Vozes, 2007), e a fenomenologia tem uma ancoragem última no empírico corpo que sente.
} 
gia da proto-intencionalidade que, ao mesmo tempo, compreende os proto-impulsos, o inconsciente e a associação como temas de uma fenomenologia progressiva. Enquanto a fenomenologia regressiva parte do dado com o fim de realizar uma análise desconstrutiva, este tipo alternativo de fenomenologia implica uma análise construtiva em relação com o que não é dado na intuição. $O$ artigo procura desenvolver essas questões em quatro passos, seguindo um fio condutor proporcionado pela noção de tensão. Em primeiro lugar, considera-se a fusão associativa enquanto implica uma tensão no sujeito e dá lugar à constituição de objetos. Em segundo lugar, mostram-se as raízes da tensão numa intencionalidade instintiva. Em terceiro lugar, examina-se a relação entre instinto e protogeneratividade. Em quarto lugar, coloca-se em relevo a significação desses temas para as noções de patência e latência. Por último, intenta-se vincular os conceitos husserlianos de tensão e intencionalidade com as noções heideggerianas de carga e ser-no-mundo" (Walton, 2002, p. 254). E para justificar a fenomenologia deste processo cita um importante parágrafo de Husserl:

Toda esta esfera é uma esfera de reconstrução, a saber, a reconstruçãoque retrocede do patente para o latente, seguindo as modificações ocorridas. Mas há reconstrução daquilo que é a consciência, que de certa forma é a experiência de uma subjetividade experienciante. Mas não é experienciante ativamente de uma maneira que permita a comunicação eficaz e legitimação de ser, e isso por princípio. Assim se passa na vida psíquica do proto-bebê (das urkindliche Seelenleben). Mas é obviamente, reconstruível (mesmo numa determinação 'vaga') e é efetivamente com o sentido de ser atribuído à reconstrução. É como uma consciência, um serpara-si, só acessível assim intersubjetivamente (Hussserl, 1973, citado por Walton, 2002, p. 259).

A remissão retroativa só é possível porque a interação intersubjetiva do ser humano a possibilita. Essa relação do latente com o patente é essencial para a fenomenologia reconstrutiva que faz um movimento para trás (Zurückfuhrung, Abbau), para então fazer o movimento de reconstrução (Aufbau). Segundo Husserl as sedimentações latentes obedece uma direção que une teleologicamente o ser humano com o movimento do mundo como um todo.

As fases do feto, da criança, as fases passadas de modo geral sofrem da não-mostração direta e intuitiva do modo de ser e precisa da fenomenologia construtiva de Fink para remontar às fases do corpo em seus primórdios por reconstrução do vínculo transcendental com o sentido das coisas: a presença de uma proto-criança ou de um proto-ego enquanto feto e o nosso ter-sido-criança nos dá uma relação com esses sentidos e aproximações fenomenológicas da relação entre gerações. Por isso podemos partir das relações transcendentais intersubjetivas para a construção do modo de ser do feto. Estamos na esfera da fenomenologia construtiva e generativa. O dar-se do sentido do feto é uma relação de sentido com o nosso modo de ser a partir do qual fomos gerados. O sentido é percebido como extensão do vínculo generativo.

Partimos da materialidade vivida do sensível no corpo que sente e as diferentes constituições desse corpo na relação do percurso de sentido que vai do sensível do corpo até as elaborações de sentido na língua através de significados. Trata-se dos muitos modos de como o sentido é apropriado, isto é, incluído no movimento do próprio ou de si mesmo. As vantagens de escalonar essas fases como: 1) Infans 2) Puer e 3) o Adulescens (seguindo a tradição clássica de escritores latinos ${ }^{14}$ ), é de colocarmos no centro a questão do sentido e sua apropriação não linguística e linguística.

O corpo e a corporeidade revelam com clareza as fases. O corpo que sente e que sente que sente (o sensível, o sentimento, o instinto, o sentido das coisas, o sentido significado em palavras, a arte, etc.) é o corpo que se expressa. Um traço imanente ao corpo é sua motricidade constitutiva ${ }^{15}$. A motricidade humana adquire com a fenomenologia um ou outro sentido que enriquece os estudos relacionados ao corpo que se move (ex., à mudança de direção que se constata hoje nos estudos da psicomotricidade). O corpo que se move é um centro irradiador da relação com o sentido. A intencionalidade do corpo vem entrançada com o movimento. Por isso, o corpo será tratado como corpo motriz que opera como um catalisador semântico.

O corpo é nossa primeira relação com o mundo enquanto sentido. O sensível não é apenas uma impressão sensível. O sensível já implica orientação para o corpo. O corpo opera o sentido sensível numa esfera passiva e pré-reflexiva. A intencionalidade que se apropria do sentido começa originariamente com movimentos que se especializam. No ser humano já é parte do processo de constituição ou desdobramento de mundo. A intencionalidade apropriante do sentido ("apropriante" no sentido esclarecido acima, de incluir no corpo próprio ou no movimento de si próprio) é potenciada pela apropriação linguística. De qualquer forma as intencionalidades do corpo e da consciência alcançam estabelecer uma relação de sentido e de apropriação do sentido em signos e significados. Nas palavras de Ricoeur:

Se a intencionalidade é a propriedade notável da consciência de ser consciência de escapar de si mesmo em direção a um outro, o ato de significar contém o essencial da intencionalidade... há uma primeira intenção que vai ao sentido como face a face estável de todos os atos de significações que querem dizer a mesma coisa (Ricoeur, 2009, p. 9-10).

\footnotetext{
${ }^{14}$ Cícero.

${ }^{15}$ Reconhecido por Aristóteles. O corpo movente, sua direcionalidade e possibilidades foram temas de estudo do Estagirita.
} 
A intencionalidade é compreendida na amplitude das relações de sentido (mais ampla que as relações de significado). A relação de sentido não se limita às significações linguísticas. É importante observar que "sentido" é uma palavra de significação múltipla que traduz em sua amplitude vários significados de “sentido”. Significa o sensível (o sentido sensível), os órgãos de sentido (os olhos, p.ex.), direção (sentido espacial), sentimento (quando alguém se mostra "sentido"), significação (um recorte ou um termo de sentido), senso ("o bom senso”, p.ex.)), etc. Essas várias significações remontam à raiz indo-europeia sent| de onde deriva a variedade de significações que apontamos e que aparece em muitas línguas. O leque que caracteriza o percurso do sentido segue as possibilidades abertas por essa raiz. Esse percurso parte de das formas pré-reflexivas de sentido da materialidade vivido do sensível (sentidos corporais, sentimento, paixão, emoção) até às formas apropriação de sentido em conceitos (ideação do sentido, sentido significado na língua, sentidos compreensivos como sentido da vida ou sentido do ser). Por isso achamos adequado utilizar a expressão relação sent-| para expressar a compreensão e amplitude do percurso do sentido da intencionalidade humana.

Do que foi dito, a fenomenologia pode ser entendida como a apropriação do sentido em significações partindo-se do corpo que sente ou da ancoragem do sentido no sensível do corpo e seus desdobramentos ou constituições até à consciência reflexiva. "Ir às coisas mesmas" é ir às coisas como são dadas entrelaçadas como vividas, pensadas e expressas em termos de sentido. Fenômeno é tudo que se manifesta na luz dessa relação de sentido. Do sensível e das noções de sentido fundadas no corpo que sente.

A fenomenologia das idades da vida estuda os desdobramentos do ser humano como corpo que sente e abre a ideação do sentido das fases do curso humano de vida. No mundo-horizonte que está na base da relação humana com o sentido se constituem muitos mundos; a correlação um mundo onde cabem muitos mundos é inerente ao pensamento fenomenológico de Husserl: o mundo-horizonte é o horizonte dos horizontes. Assim podemos pensar o desdobramento de mundos que constituem as fases da vida humana em relação com seu corpo e a apropriação de sentido em cada fase ou sub-horizontes do mundo. Na apropriação se constituem mundos em torno de sentidos e significados que formam conjuntos mais ou menos estruturados. Como correlato da apropriação e constituição de mundo ocorre o desdobramento da subjetividade. A subjetividade constitui o campo de esfera de si próprio que busca autonomia e liberdade numa dinâmica de apropriação (inclusão na dinâmica de si mesmo) ou desapropriação (quando algo escapa dessa dinâmica voluntária de si mesmo). O processo de apropriação e desapropriação forma uma dinâmica constituindo uma esfera de jogo em torno da memória e da imaginação, essas entendidas como processos dinâmicos e criativos com conteúdos formados ativa e passivamente. Nesses jogos de si mesmo o outro é fator fundamental.

As questões fundamentais para uma fenomenologia das idades da vida, essencialmente uma fenomenologia generativa, podem ser sumariadas como segue:

1. O corpo é uma totalidade motriz sensiente que não se explica pelas partes funcionais. Antes da consciência intencional o corpo humano revela camadas de intencionalidade pré-conscientes. O esforço de existir segue o ímpeto de formação que une natureza e cultura. A natureza garante a formação da espécie, não a apropriação da existência.

2. As fases da vida são totalizações ou sínteses integradoras onde as fases subsequentes incorporam novas relações possíveis. Trata-se de um corpo só com várias fases integradoras. Não somos a fase de vida que vivemos de modo isolado. Somos um todo integrador de sentido por fases que não se excluem. A descrição da estrutura e da existência do ser humano que visa só o adulto não dá conta da existência humana como um todo.

3. O corpo, desde a fase fetal, não se resume a funções fisiológicas. A totalização ou síntese integradora de uma nova fase não é uma soma quantitativa de funções ou órgãos de ordem fisiológica, mas integra uma nova relação com o mundo. A motricidade não é apenas um modo do corpo material sensível; em novas sínteses integradoras assume também a o movimento pensante e o fluir da consciência em relação ao sentido das coisas.

4. Cada fase tem seu modo próprio de relação com mundo: "que não é apenas mundo físico, mas mundo de sentido" (Le Breton, 2009, p. 70); o corpo humano delimita sua corporeidade em relação de sentido (relações sent.-l) que vai dos sensíveis diferenciados corporalmente, aos sentidos delimitados em significados ou termos linguísticos. As transformações realizam modos de encarnar o mundo como horizonte de sentido.

5. O corpo senciente não se desdobra em sua relação com o sentido sozinho; desdobra-se em fases por interação com os outros (e com a cultura). Ao mesmo tempo cada fase traz novos horizontes de autonomia por novos processos de apropriação. Cada fase tem seu modo próprio apropriação e de constituição de um pré-si e de um si mesmo, como forma de entrar no jogo de si mesmo com os outros.

6. O corpo enquanto relação de sentido vive o horizonte mundo onde muitos mundos são possíveis (perspectiva husserliana, cf. Benoist, 1998)).

7. O sistema simbólico de relações de sentido de índice mais abrangente em termos de apropriação é a língua; aqui a tomamos como categoria para definir as fases da vida, segundo o modo de apropriação, em não-falante ou pré-falante (infans, fase fetal e pós-parto antes da absorção efetiva da língua), falante-criança (aqui denominada puer) e a falante adulescens, quando o corpo e as relações com o mundo entram numa outra fase ou síntese integradora de si com o mundo. 
8. A relação de sentido do corpo com o mundo não é um sistema fechado. Depende da comunhão originária em diferentes níveis com o outro (intersubjetividade originária começa com o outro).

9. As fases integradoras acontecem de modo fundado nas fases anteriores. A materialidade vivida originária do sentido é o início de um percurso do sentido em fases que revelam que o ser humana age segundo as possibilidades de apropriação de cada fase.

10. "Mundo" fenomenologicamente não é originariamente o mundo físico. Mundo ou horizonte do mundo é horizonte de sentido na relação do corpo sensiente. $\mathrm{O}$ ser humano no mundo sente de vários modos e em varias modalidades de sentido.

A abordagem proposta depende de uma distinção que aparece em alguns fenomenólogos (e.g., Merleau-Ponty, Ricoeur) e, especialmente, no último Husserl, entre sentido e significado ${ }^{16}$ Essa distinção reserva o termo "sentido" para uso muito mais amplo que "significado". "Sentido" se refere a várias modalidades de suas manifestações em nosso ser-no-mundo e implica uma hermenêutica num âmbito maior de manifestação (que começa com o sentir algo e a percepção); a significação é um recorte de sentido, um "termo", frase ou discurso (embora uma significação tenha sentido, sentido é mais amplo que significação) cuja interpretação ocorre na língua, obedecendo aos recortes feitos, mas também atendendo a muitas possibilidades de sentido (Cf. Josgrilberg, 2015). A experiência do sentido se inscreve em nosso modo de ser no mundo como um todo. A língua é um dos modos da experiência do sentido, essencial por sua abrangência e potência, mas ela não é a fonte originaria do corpo sensiente, ainda que sua manifestação seja capaz de interpretar outros modos de sentido. A relação de sentido é uma relação que acompanha a disposição do corpo humano para os sentidos; a língua é apenas um dos modos humanos mais fundamentais de apropriação do sentido.

\section{Referências bibliográficas}

Benoist, J. (1998). O mundo para todos: universalidade e Lebenswelt no último Husserl. Em Discurso, USP, n. 29, p. 209-238.

Depraz N. (2007). Compreender Husserl. Petrópolis: Vozes.

\footnotetext{
16 "In his Logical Investigations, Husserl tends to use the terms Sinn, Bedeutung and also Meinung more or less as equivalent notions, although later, in his Ideas I, par. 124, he will restrict Bedeutung to linguistic meaning only and use Sinn more broadly to include all meanings, including non-conceptual contents (e.g., perceptual sense).” Dermot Moran (and J. Cohen), The Husserl Dictionary, London/N. York, Continuum Int. Pub. Group, 2012, p. 296. "The fourth phase of Husserl's thinking about meaning is to be found in the Ideen I (1913), where a distinction is made between sensuous perceptual meanings (now called Sinne) and their transformations into conceptual and logical form (now called Bedeutung), the later being expressible in language." J. Mohanty no verbete Meaning, in Encyclopedia of Phenomenology, ed. By L. Embree et al. Dordrecht, Springer, 1997, p. 443-444.
}

Erasmo de Roterdam (s/d) De Pueris. São Paulo: Ed. Escala.

Hesnard, A., Psychanalyse du lien interhumain, Paris, Puf., 1957

Husserl, E. (2013). Hua. XLII: Grenzprobleme der Phaenomenologie. Analysen des Unbewusstseins und der Instinkte. Metaphysik. Späte Ethik. Texte aus Nachlass (1908-1937). Springer, Dordrecht.

Husserl, Ed. (1973). Hua XV: Zur Phänomenologie der Intersubjektivität. Texte aus dem Nachlass. 1929-1935. La Haya M. Nijhof.

Husserl, Ed. (1952). Hua.IV: Ideen zu einer Reinen Phänomenologie und phänomenologischen Philosophie II. La Haya M. Nijhof.

Husserl, Ed. (2008). Hua, XXXIX: Die Lebenswelt. Auslegungen der vorgegebenen Welt und ihrer Konstitution Texte aus dem Nachlass (1916-1937). Springer, Dordrecht.

Josgrilberg, R. (2015). Sentido e significação: uma essencial distinção hermenêutica. em Nogueira, P. (Org.) Religião e Linguagem. Abordagens teóricas interdisciplinares (p. 341-372). São Paulo: Paulus.

Le Breton, D. (2009). As paixões ordinárias. Antropologia das emoções. Petrópolis: Vozes.

López López, A. F. (2016). Vida humana fenomenológica. Balance sobre la relación entre sujeto humano y el sujeto trascendental en la fenomenología de Edmund Husserl. Em Ideas y Valores, 65.161, p. 157-184.

Perkins, P. (2011). El vínculo madre-hijo como suelo del destino. Contrastes: Revista Internacional de Filosofía, XVI, p. 313-329.

Ricoeur, P. (2009). Na escola da fenomenologia. Petrópolis: Vozes.

Rizo-Patrón de Lerner, R. (s/d) "Constitución teleológica de la identidad, del instinto a la razón”. Recuperado em janeiro de 2016, de http://textos.pucp.edu.pe/pdf/4623.pdf.

Séville, I. (s/d). Etymologiae, XI. Madrid.

Spitz, R. (1954). La première année de la vie de l'enfant. Paris : PUF.

Taguchi, S. (2006). Das Problem des,Ur-Ich` bei Edmund Husserl. Springer-Verlag.

Walton, R. (2002). "Instintos, generatividad y tensión en la fenomenología de Husserl”. Em Revista Natureza Humana, 4/2 (jul.-dez), p. 253-292.

Rui de Souza Josgrilberg - É graduado em Filosofia pela Universidade de Mogi das Cruzes (1976), graduado em Teologia pela Universidade Metodista de São Paulo (1967) e doutor em Sciences Religieuses pela Université de Strasbourg (1973). Atualmente é professor titular da Universidade Metodista de São Paulo. E-mail: rmbrilhante@icloud.com

Recebido em 21.02.17

Revisões 28.03.2017

Aceito em 12.04.17 